\title{
Bringing telehealth to humanitarian settings
}

I $\mathrm{n}$ the midst of a conflict in the Middle East, a team of physicians frantically operates on a young man with a gunshot wound in the leg. After blood flow to his leg is restored through a venous graft, they find themselves wondering about managing his care. Does he need to take daily aspirin for the rest of his life? Does he need to be prescribed warfarin? In an urban hospital with large professional resources, these questions would be answered easily by conferring with colleagues. Here, unfortunately, they are on their own.

To mitigate this problem, international aid organizations are increasingly using an innovation familiar to many Canadian physicians: telemedicine. Conceived initially with telephone communications in mind, the Internet has expanded telemedicine's scope and reach. Today, it is often used in lowresource settings globally.

Médecins Sans Frontières (MSF), an international humanitarian organization, has been using telemedicine since 2010. Its service was developed initially in 2009 by Dr. Laurent Bonnardot, an MSF-France physician, who was inspired by the need to bring the expertise of consultants who are often not long-term members of MSF teams, to the field.

Since the first referral, the portal has logged 1301 cases from 243 referral sites across the globe. The top referring countries are the Central African Republic, Malawi and South Sudan. In an initial evaluation of 300 field users in 2014 conducted by MSF, $91 \%$ of users found the portal helpful; $81 \%$ said it improved patient management in the field.

Dr. Raghu Venugopal, an emergency physician at the University Health Network in Toronto, has been helping MSF manage and develop its telemedicine tool since 2013. While on missions with MSF in Burundi, the Democratic Republic of Congo and most recently the Central African Republic, he experi-

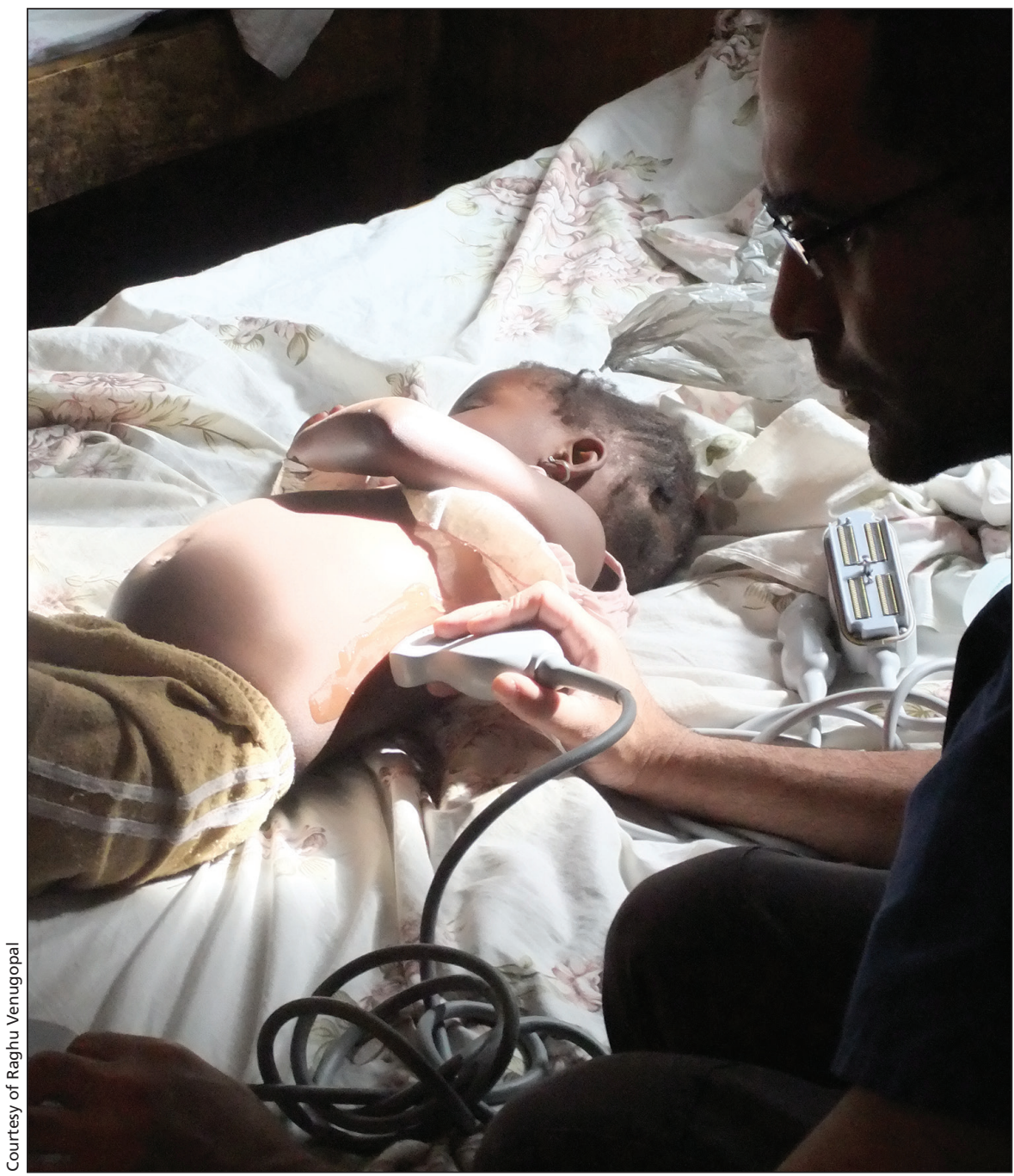

Dr. Raghu Venugopal, a proponent of using telehealth in the field, performs ultrasound on a child during a recent mission.

enced the benefits of being able to access the expertise of medical colleagues from around the globe.

"Often times, doctors and nurses are working alone, without any back-up or additional support, and limited resources." When asked for an example of how the portal is used in the field, he recounted the incident that opened this article. That story ended well. Through the portal the isolated field personnel were connected to a Spanish vascular surgeon who provided guidance on the longterm management of the patient.

The MSF telemedicine program is now accessible online through satellite telephones provided to staff. Doctors $\log$ in with a secure username and password and remove all patient identifiers from images that are uploaded to the site. Cases are assigned to consultants virtually, depending on the area of expertise. To date, there are 271 participating physician consultants serving the field through the portal, including about a dozen Canadians.

The consultants are expected to respond within 24 hours, with fieldappropriate information that is high quality and, most important, pragmatic 
given the setting. Through the portal, they can access some metrics about the capacity of each field site, helping them to make informed recommendations. To ensure the quality, helpfulness and timeliness of referrals, MSF telemedicine portal system administrators, such as Venugopal, pick a case at random every month and review it.

The MSF system has a definite Canadian slant. The organization's international president and its former Canadian president, Montrealer Dr. Joanne Liu, "was critical in convincing MSF offices and workers of the utility and potential of the telemedicine system," says Venugopal. It wasn't only theoretical support either. "She served as a systems operator, responsible for allocating cases to specialists and managing the day-to-day operations of the portal."

The portal is still a work in progress and not all MSF field sites use it. Venugopal's team is working to raise awareness. "Doing telemedicine is not the average experience for most people in their medical practice at home. But consulting specialists is something we all do. We just have to change the mindset [of physicians]." Increasing the portal's reach and physician involvement will help improve its impact.

"This is about delivering the best possible care, to the worst off patients." - Moneeza Walji, CMAJ

CMAJ 2015. DOI:10.1503/cmaj.109-4987

Editor's note: Interested in learning more about MSF's telemedicine initiative? Watch the video: https://www.youtube.com /watch?v=2R8VWae $35 \mathrm{~m} 0$ 